\title{
CAROTID DIAPHRAGM - A RARE OR AN UNRECOGNIZED ENTITY ?
}

\author{
Censori B, Cellerini M*, Gallizioli G*, Partziguian T, Bonaldi G*, Rottoli MR \\ USC Neurology and * USC Neuroradiology, ASST- Papa Giovanni XXIII, Bergamo, ITALY
}

Introduction. Carotid diaphragm (CD), also called carotid web (1), is considered a focal form of fibromuscular dysplasia (2), and a rare causes of ischemic stroke. We have collected three cases of $\mathrm{CD}$ over a 2-year period, suggesting that its frequency may be higher than previously thought.

Patients and Methods. We have prospectively collected all cases of CD among patients with ischemic stroke or TIA admitted to our Stroke Unit during the last two years. A CD was diagnosed when CT- or MR-angiography (CTA-MRA) showed the image of a spur arising from the posterior wall of the carotid and a thin septum in axial images, without signs of atherosclerosis of the ipsilateral bifurcation.

Results. Out of 671 patients, $316(47,1 \%)$ underwent CTAMRA. Three cases showed a CD $(0.45 \%$ overall, $0.95 \%$ of CTAMRA). They were 3 women aged 34, 59, and 64 years. The 59 year old patient had no known cerebrovascular risk factors. She had had a previous ipsilateral territorial stroke 7 years before the index event, and was taking aspirin at the time of her second territorial stroke. Workup for hypercoagulability and vasculitis, the bubble test and TEE were negative. Prolonged ECG showed sinus rhythm, and Duplex ultrasound showed focal thickening at the carotid bulbs. The CD was bilateral, but more prominent on the symptomatic side. Intra-arterial digital subtraction angiography (DSA) confirmed the carotid diaphragm (Fig. 1A), and showed persistent contrast stagnation behind the diaphragm (Fig. 1B and C). She underwent stenting of the lesion, without complications. The 34 year old patient was a black women without cerebrovascular risk factors, with a first-in-life left middle cerebral artery territorial stroke. Duplex ultrasound showed a thick spur at the left carotid bulb, which appeared slightly thinner after a few days, perhaps suggesting the resolution of an overlying thrombus. The spur was also confirmed at CT angiography and DSA (Fig. 2). Workup for hypercoagulability and vasculitis, the bubble test and TEE were negative. She also underwent stenting of the lesion, without complications. The 64-year-old case had a symptomatic contralateral atherosclerotic carotid occlusion, while the CD was asymptomatic (Fig. 3; axial view). No old ischemic lesions were visible ipsilaterally at CT scan.

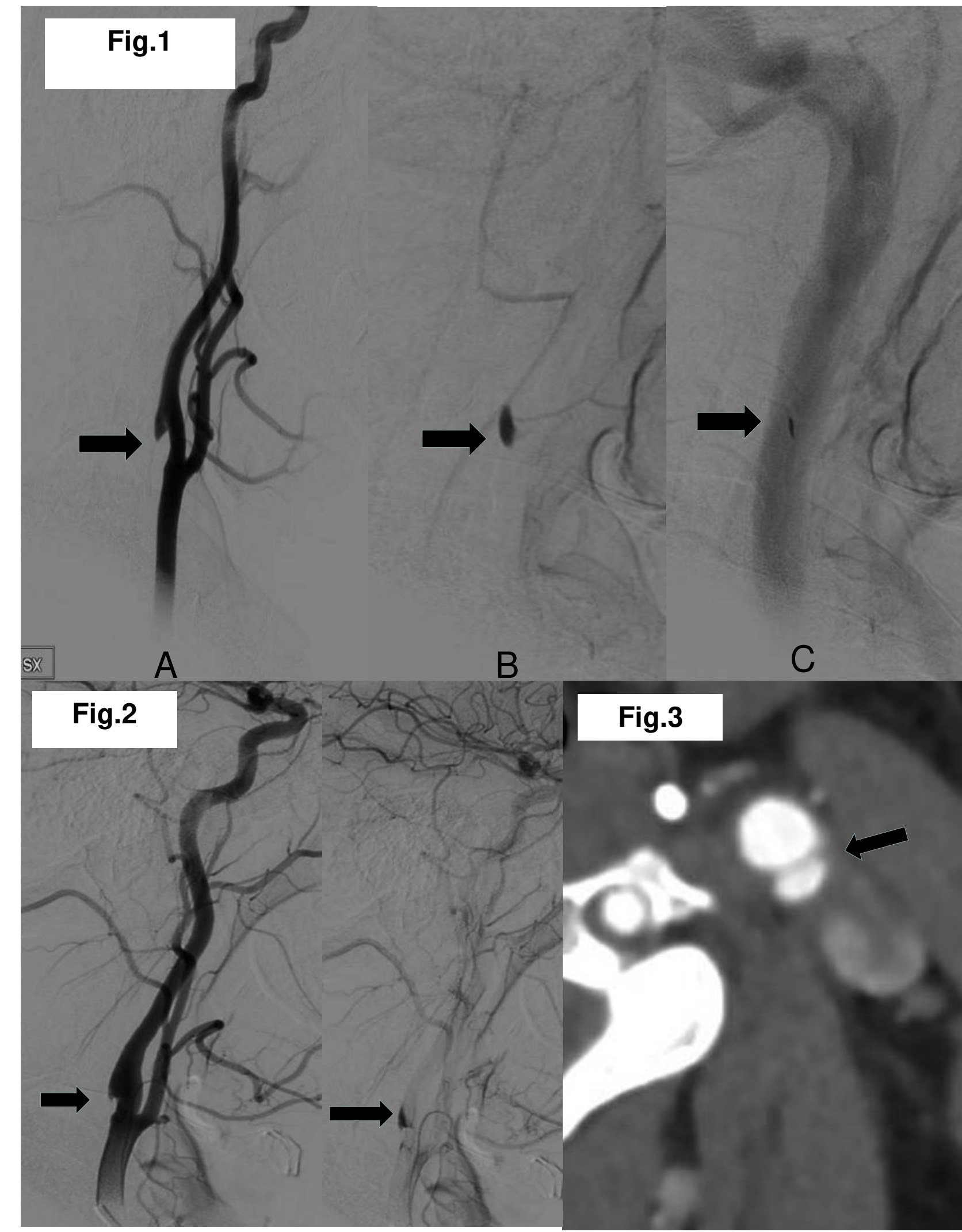

Conclusions. Although infrequent, a carotid diaphragm seems to be not so exceptional among patients with ischemic stroke or TIA. Recent series of consecutive CT- angiography or DSA have found $\mathrm{CD}$ with a frequency of 1.2-2.5\% $(1,3)$, not very different from ours. This frequency may be much higher among younger women with cryptogenic strokes $(9.4 \%$ in the series of Coutinho et al)(4,5), as also seen in our cases. A high index of suspicion is necessary to find a $\mathrm{CD}$, because it is rarely seen on Duplex ultrasound. Differentiation from mural thrombus or atherosclerotic lesions may not be straightforward in all cases (1, $6)$. If these data are confirmed, a not so small fraction of cryptogenic strokes may have found its cause.

\section{References}

1. Choi PMC, Singh D, Trivedi A et al. Carotid webs and recurrent ischemic strokes in the era of CT angiography. AJNR 2015;36:2134-2139

2. Lenck S, Labeyrie MA, Saint-Maurice JP, Tarlov N, Houdart E. Diaphragms of the carotid and vertebral arteries : an under-diagnosed cause of ischaemic stroke. Eur J Neurol 2014;21:586-593

3. Compagne KCJ, van Es AGCM, Berkhemer OA et al. Prevalence of carotid web in patients with acute intracranial stroke due to intracranial large vessel occlusion. Radiology 2018;286:1000-1007

4. Sajedi PI, Gonzalex JN, Cronin CA et al. Carotid bulb webs as a cause of "cryptogenic" ischemic stroke. AJNR 2017;39:1399-1404

5. Coutinho JM, Derkatch S, Potvin ARJ et al. Carotid artery web and ischemic stroke. Neurology 2017;88:65-69

6. Chaari D, Baud JM, Deschamps L et al. Carotid diaphragm : atypical fibromuscular dysplasia or atheromatous lesion ? Rev Neurol 2017;173:230-233 